\title{
Comparison of the efficacy of ropivacaine and ropivacaine with dexmeditomidine in post tonsilectomy pain relief after peritonsillar infiltration- A prospective randomized double blind study
}

\author{
Rahul Singh ${ }^{1}$, Lopa H Trivedi ${ }^{2}$, Ravikumar M Parmar ${ }^{3^{*}}$ \\ ${ }^{1}$ Resident, ${ }^{2}$ Associate Professor, ${ }^{3}$ Assistant Professor, Dept. of Anaesthesiology, Government Medical College, Bhavnagar, Gujarat, India \\ *Corresponding Author: Ravikumar M Parmar \\ Email: rahulsingh.1930@gmail.com
}

Received: $31^{\text {st }}$ January, 2019

Accepted: $18^{\text {th }}$ March, 2019

\begin{abstract}
Introduction: Post operative pain relief is desired goal after tonsillectomy, infiltration of local anesthetic with or without adjuvant can reduce post tonsillectomy pain.

Objective: To compare the postoperative analgesic efficacy and side-effects of peritonsillar-infiltration of ropivacaine with or without dexmeditomidine.

Materials and Methods: Sixty patients aged 4-14 years posted for tonsillectomy under GA were randomly assigned in two groups of 30 each. In group R: Inj. ropivacaine $(0.5 \%) 0.2 \mathrm{ml} / \mathrm{kg}$ and in group RD: Inj.ropivacaine $(0.5 \%) 0.2 \mathrm{ml} / \mathrm{kg}+\mathrm{Inj}$. dexmeditomidine $1 \mathrm{mcg} / \mathrm{kg}$ were infiltrated in peritonsillar fossa post tonsillectomy. Patient were monitored for post-operative pain using VAS score, CHEOPS score and Wong baker pain rating scale at 30 minute, $1 \mathrm{hr}, 2 \mathrm{hr}, 4 \mathrm{hr}, 10 \mathrm{hr}, 16 \mathrm{hr}$ and $24 \mathrm{hr}$, pain on deglutination, time to first analgesic requirement, total dose of analgesics requirement in $24 \mathrm{hr}$ postoperatively, amount of bleeding and parent's satisfaction score.

Results: VAS score, CHEOPS and Wong baker pain rating scale were comparable in both the groups at $30 \mathrm{~min}, 1 \mathrm{hr}, 2 \mathrm{hr}(\mathrm{P}>0.05)$ but it was significantly low in group RD as compared to group $\mathrm{R}$ at $4 \mathrm{hr}, 10 \mathrm{hr}, 16 \mathrm{hr}$ and $24 \mathrm{hr}(\mathrm{P}<0.05)$. Time for first analgesia, total analgesic requirement, pain on deglutition were significantly low in group $\mathrm{RD}$ compared to group $\mathrm{R}(\mathrm{P}<0.05)$ and parents satisfaction score was significantly more in group RD.

Conclusion: We concluded, peritonsillar infiltration of ropivacaine with or without dexmeditomidine is effective method for posttonsillectomy pain relief. Addition of dexmeditomidine was found to prolong duration, decrease analgesic requirement and improve parent's satisfaction score.
\end{abstract}

Keywords: Tonsillectomy, Visual analog score, CHEOPS, Wong baker pain rating scale, Ropivacaine and dexmeditomidine.

\section{Introduction}

Tonsillitis is an infection of tonsil, more common in school going children (4-10yr). Tonsillectomy is one of the most common surgical procedures performed annually in children younger than 15 years. ${ }^{1}$

Tonsillitis if, acute treated conservatively and the treatment consists of attention to general health, diet, treatment of coexistent infection of teeth, nose and sinuses. Tonsillectomy is considered when tonsils interfere with speech, deglutition, and respiration and in cases of recurrent tonsillitis.

Tonsillectomy can cause severe pain postoperatively, which hinders mastication and swallowing, hence nourishment which, in turn, causes a delay in wound healing, dehydration, loss of several work or school days and weight. These collectively lead to prolonged hospitalization, psychosocial problems in patients as well as placing a financial burden and causing loss of manpower. ${ }^{2}$ If postoperative pain is controlled in the best possible way it may smoothens the recovery period. Postoperative pain control, especially in paediatrics population continues to be a big challenge for anesthesiologist as definite ideal method of pain relief is not yet known. ${ }^{3}$

Postoperative inflammation and spasm of the pharyngeal muscles have been shown to cause ischemia in the tonsillar fossa which in turn prolongs the pain cycle. ${ }^{4}$ In an attempt to decrease post tonsillectomy pain, various peri-operative adjuvant therapies such as steroids, analgesics, antibiotics and local anaesthetic infiltration have been tried. ${ }^{5}$ Local anaesthetic infiltration seems to be logical choice as it can block the nerve conduction when infiltrated in peritonsillar fossa. ${ }^{6}$ Although benefits and complications of this technique is not established yet, it is an attractive choice as it is relatively safe method of pain control in children, who often exhibit resistance to intramuscular or rectal administration of drugs. $^{7}$

Different local anaesthetics can be used for infiltration but the ropivacaine which has least neuro and cardio toxicity and selective sensory effect will be the better choice. Ropivacaine was studied for analgesia after tonsillectomy locally in different concentration $0.25 \%, 0.50 \%$ and $1 \%$, it significantly relieves post-tonsillectomy pain in the pediatric population and also reduces postoperative analgesic requirement..$^{8-9}$ There are several studies which suggest dexmeditomidine a highly selective alpha 2 agonist and dextroisomer of medetomidine is known to improve quality of anaesthesia and post operative analgesia without causing side effects. ${ }^{9-10}$

So we have decided to study the postoperative analgesic efficacy of postoperative peri-tonsillar infiltration of ropivacaine and ropivacaine with dexmeditomidine in children undergoing tonsillectomy. 


\section{Materials and Methods}

After approval from the Institutional Review Board [(IRB No. 681/2017) \& CTRI registration (CTRI No. /2017/10/009983) and informed written consent in local language from the parents of the children, this prospective, randomized, double blind study was carried out in the Department of Otorhinolaringology, Govt. Medical College and Sir. T. Hospital, Bhavnagar, Gujarat. After through pre anaesthetic evaluation, 60 patients of either sex, aged 4-14yr posted for tonsillectomy under general anaesthesia were enrolled in this study according to following criteria.

\section{Inclusion Criteria}

1. Age of patient: 4-14 years

2. Gender: male and female

3. Patients posted for tonsillectomy or adenotonsillectomy under general anaesthesia

4. ASA Grade I \& II

\section{Exclusion Criteria}

1. Acute pharyngeal infection

2. Peri-tonsillar abscess

3. Cardiovascular, renal or liver disease

4. Neurological or psychiatric disease

5. Coagulation disturbances

6. Allergy to local anaesthetic

Patient were randomised into 2 groups $(n=30)$ using computer generated random number sequence method. Patients were blinded about the group in which they were enrolled.

Group R ( $\mathrm{n}=30)$ : will receive Inj. ropivacaine $(0.5 \%)$

$0.2 \mathrm{ml} / \mathrm{kg}+$ Normal saline $.01 \mathrm{ml} / \mathrm{kg}$

Group RD ( $\mathrm{n}=30)$ : will receive Inj. ropivacaine $(0.50 \%)$

$0.2 \mathrm{ml} / \mathrm{kg}+$

Inj. dexmeditomidine $1 \mathrm{mcg} / \mathrm{kg}$ )

Patients and parents were explained for Visual Analogue Scale (VAS) during pre anaesthetic check-up.

\section{Visual analogue scale (VAS)}

The visual analogue scale is represented as a straight line usually $10 \mathrm{~cm}$ in length: 0 -No pain and 10 -worst pain ever (as shown in Fig. 1). For children it could be simplified by adding pictures. Child places a slide corresponding to the degree of pain they feel. This seems to be the most sensitive method.

This method has been used in this study for pain score assessment in children.

After shifting the patient to the pre anaesthetic care room, 22G intravenous catheter is inserted on non-dominant hand; Monitoring device include ECG, pulse -oximeter, noninvasive blood pressure were attached. Premedication was given using inj. Ondensetron $0.8 \mathrm{mg} / \mathrm{kg}$, Inj. Glycopyrolate $0.004 \mathrm{mg} / \mathrm{kg}$, Midazolam $0.02 \mathrm{mg} / \mathrm{kg}$ and inj Tramadol $2 \mathrm{mg} / \mathrm{kg}$.

Patients were shifted to operation theatre and intraoperative monitoring was done for heart rate (ECG), $\mathrm{Spo}_{2}$ (Pulse Oximeter), Blood pressure (Non Invasive Blood Pressure). All patients were anaesthetized using standard general anaesthetic technique. Pre oxygenation was done with $100 \%$ oxygen for 3 min. Induction was done using Inj.sodium thiopental 2.5\% till loss of eye lash reflex and Inj. succinylcholine $2 \mathrm{mg} / \mathrm{kg}$, to facilitate oro-tracheal intubation and appropriate sized portex cuffed endotracheal tube was used for endotracheal intubation. Oropharyngeal packing was done using sterile cotton roll soaked in distil water, anaesthesia was maintained with oxygen, nitrous oxide, sevoflurane, intermittent atracurium and intermittent positive pressure ventilation.

Tonsillectomy was done by using Snare technique. Digital pressure was applied using saline soaked gauze piece for 10 minutes after tonsillectomy to stop oozing if any. After confirming that there is no bleeding and surgery is over, the peri tonsillar tissues on both sides was infiltrated in a fanwise injections from the superior and inferior poles of the fossa according to assigned group using a 24 gauge 1 inch needle connected to a syringe. Syringe was filled by one of the team member not involved in the postoperative assessment of the patient.

After completion of the surgery, neuromuscular blockade was reversed using inj.neostigmine $0.05 \mathrm{mg} / \mathrm{kg}$ and inj.glycopyrolate. $008 \mathrm{mg} / \mathrm{kg}$. Trachea was extubated after fulfillment of the clinical criteria for extubation and thorough oropharyngeal suction. Patient was given secretion draining position and shifted to post anaesthetic care unit Oxygen was supplemented for 2 hours post operatively when child was able to maintain $\mathrm{Spo}_{2}>95 \%$ on air it was discontinued.

After the surgery patients were sifted to PACU room and when fast tracking score of $\geq 12$ they were shifted to ward. Patient's were monitored for PR and $\mathrm{Sp}_{2}$ (pulseoximeter), blood pressure, post-operative pain, pain on deglutination, time to first analgesic requirement, total dose of analgesics requirement in 24 hours postoperatively, amount of bleeding and parent's satisfaction score and complication if any at $30 \mathrm{~min}, 1 \mathrm{hr}$ and $2 \mathrm{hr}, 4 \mathrm{hr}, 10 \mathrm{hr}, 16 \mathrm{hr}$ and $24 \mathrm{hr}$.

Post tonsillectomy pain was assessed subjectively using VAS score and objectively by CHEOPS (Table 1 ) and Wongbaker pain rating scale (Fig. 2).

The rescue analgesia was given in post-operative period when VAS (Visual analogue score) $\geq 4$ or/and CHEOPS (Children's Hospital of Eastern Ontario Pain Scale) $\geq 5$ in the form of Inj. Paracetamol $10 \mathrm{mg} / \mathrm{kg}$. The time to first analgesia and total analgesic requirement in 24 hours was also calculated.

Pain on deglutition, amount of bleeding and parent's satisfaction score were monitored with verbal rating scale (VRS)

\section{Verbal Rating Scale (VRS)}

1. Mild

2. Moderate

3. Severe

\section{Statistical Analysis}

Sample size calculation assuming $\alpha$ error being 0.05 and $\beta$ error being 0.2 with a power of study $80 \%$ showed that 30 patient was required per study group to compare the effect of ropivacaine and ropivacaine with dexmeditomidine in peritonsillar infiltration after tonsillectomy. The data entry was done in Microsoft Excel 2010 and the data analysis was done in Graph Pad in Stat. Frequencies and percentages were 
calculated and p-value was established to find a statistical difference between the variables. The significance level was set at $p$ value $<0.05$. Chi-square test was also applied for the analysis.

\section{Observation and Results \\ Demographic Data}

Patient characteristics in terms of age, gender, weight and height were comparable among the two groups $(\mathrm{p}>0.05)$.

VAS score (Fig. 3) CHEOPS score (Fig. 4) and Wong baker pain rating score (Fig. 5) was comparable in both the groups at 30minute, 1 hour and 2 hour $(\mathrm{P}>0.05)$ and it was significantly low in group RD compare to group $\mathrm{R}$ at 4 hour, 10 hour, 16 hour and 24 hour ( $\mathrm{P}$ Value $<0.05$ ).

Fast tracking score before leaving operating room was comparable in both the groups $(\mathrm{P}>0.05)$ (Table 2) Time for first analgesic requirement is comparable in both the groups $(\mathrm{P}>0.05)$. (Table 3$)$. Total number of patients required analgesia was significantly low in group RD compare to group $\mathrm{R}$ (Table 4). Total analgesic consumed in group RD $(31 \pm 82.8) \mathrm{mg}$ and is significantly low as compare to that in group R $(214.6 \pm 142.8) \mathrm{mg}(\mathrm{P}<0.05)$. Post-operative pain on deglutition was significantly lower in group RD compare to that in group $\mathrm{R}$ ( $\mathrm{P}<0.05)$. Post-operative bleeding was significantly low in group in $\mathrm{RD}(1.13 \pm 0.43)$ as compare to that in group $\mathrm{R}(2 \pm 0.26)(\mathrm{P}<0.05)$. Parent's satisfaction score was significantly more in group RD $(2.80 \pm 0.40)$ as compare to that in group $\mathrm{R}(1.96 \pm 0.31)(\mathrm{P}<0.05)$.

Table 1: CHEOPS Score

\begin{tabular}{|l|l|c|}
\hline Parameter & \multicolumn{1}{|c|}{ Finding } & Score \\
\hline Cry & No crying & 1 \\
& Moaning & 2 \\
& Crying & 2 \\
& Screaming & 3 \\
\hline Facies & Smiling & 0 \\
& Neural facial expression & 1 \\
& Grimace & 2 \\
\hline Verbal & Positive & 0 \\
& None & 1 \\
& Complain other than pain & 1 \\
& Pain complain & 2 \\
& Pain and non pain complain & 2 \\
\hline Torso position & Inactive torso & 1 \\
& Shifting & 2 \\
& Tense arched or rigid & 2 \\
& Shivering & 2 \\
& Upright & 2 \\
& Restrained & 2 \\
\hline Touch & No touching of the painful area & 2 \\
& Trying to reach but not touching painful area & 2 \\
& Touching the painful area & 2 \\
\hline Legs & Grabbing the painful area & 1 \\
& Legs at rest & 2 \\
& Squirming/kicking & 2 \\
& Drawn up or tense & 2 \\
& Standing,kneeling or squatting & \\
& Restrained & \\
& & 2 \\
\hline
\end{tabular}

SUM (points for all 6 parameters)

Interpretation:

- Minimum score: 4

- Maximum score: 13 
Table 2: Fast tracking score comparison between groups

\begin{tabular}{|c|c|c|c|}
\hline & $\begin{array}{c}\text { Group R } \\
\mathbf{n = 3 0}\end{array}$ & $\begin{array}{c}\text { Group RD } \\
\mathbf{n = 3 0}\end{array}$ & P Value \\
\hline $\begin{array}{c}\text { Number of patients with } \\
\text { score of } \geq 12\end{array}$ & $\begin{array}{c}26 \\
(86.66 \%)\end{array}$ & $\begin{array}{c}28 \\
(93.33 \%)\end{array}$ & 0.330 \\
\hline
\end{tabular}

Table 3: Time for first analgesic intake

\begin{tabular}{|c|c|c|}
\hline $\begin{array}{c}\text { Group R } \\
\mathbf{n = 3 0} \\
\text { Mean } \pm \text { SD }\end{array}$ & $\begin{array}{c}\text { Group RD } \\
\mathbf{n = 3 0} \\
\text { Mean } \pm \text { SD }\end{array}$ & P Value \\
\hline $9.83 \pm 4.75$ & $11.5 \pm 3.00$ & 0.506 \\
\hline
\end{tabular}

Table 4: Total number of patients required analgesia

\begin{tabular}{|c|c|c|}
\hline Time & $\begin{array}{c}\text { Group R } \\
\mathbf{n = 3 0} \\
\text { Number of patients required analgesia }\end{array}$ & $\begin{array}{c}\text { Group RD } \\
\mathbf{n = 3 0} \\
\text { Number of patients required analgesia }\end{array}$ \\
\hline 30 minute & 0 & 0 \\
\hline 1 Hour & 0 & 0 \\
\hline 2 Hour & 0 & 0 \\
\hline 4 Hour & $6(20 \%)$ & 0 \\
\hline 10 Hour & $14(46.66 \%)$ & $3(10 \%)$ \\
\hline 16 Hour & $03(10 \%)$ & $1(3.33 \%)$ \\
\hline 2 Hour & $01(3.33 \%)$ & 0 \\
\hline
\end{tabular}

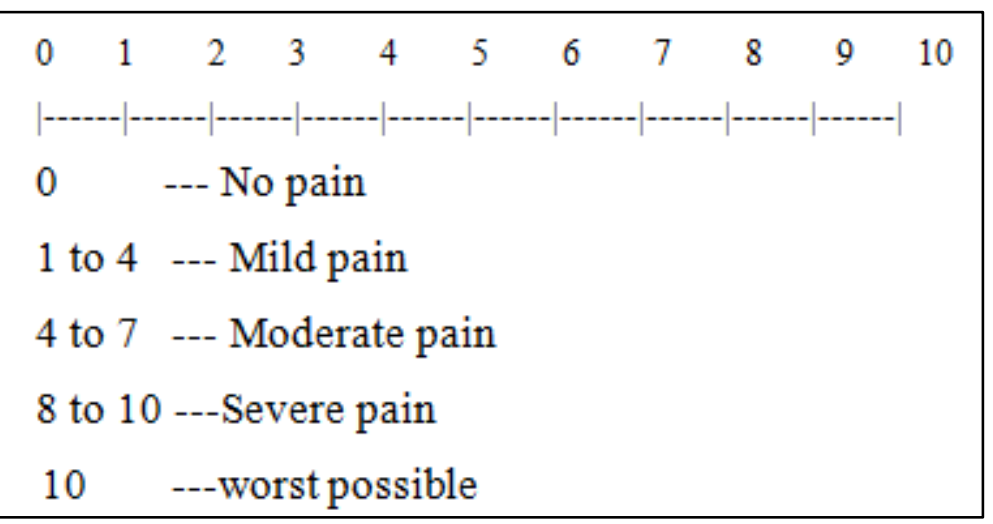

Fig. 1: VAS scale

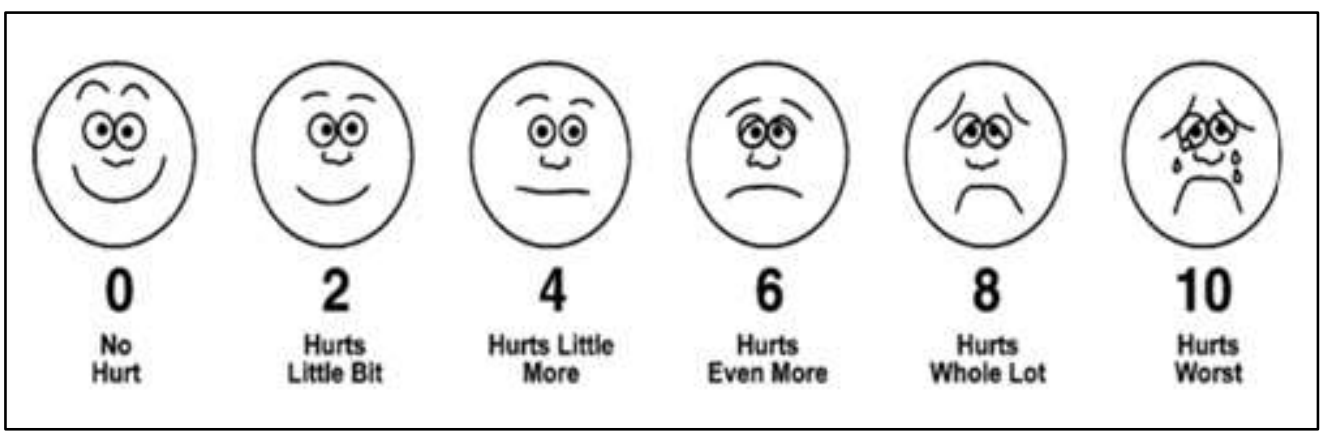

Fig. 2: Wong baker faces pain rating scale 


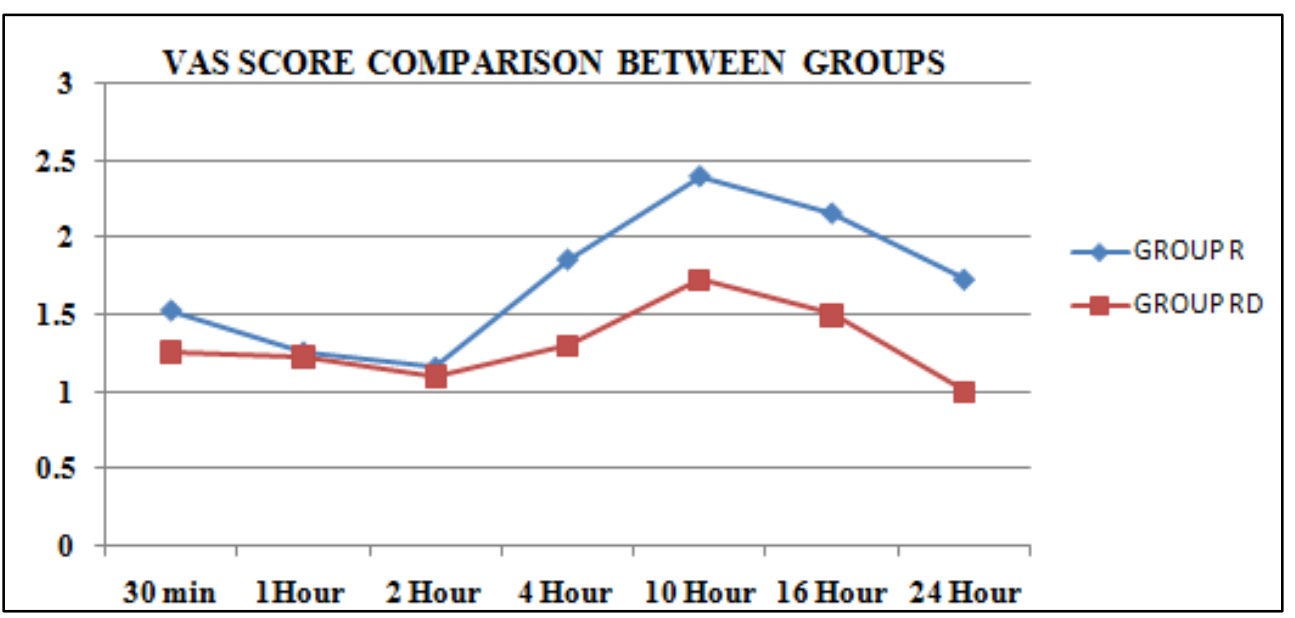

Fig. 3: VAS score comparison between groups

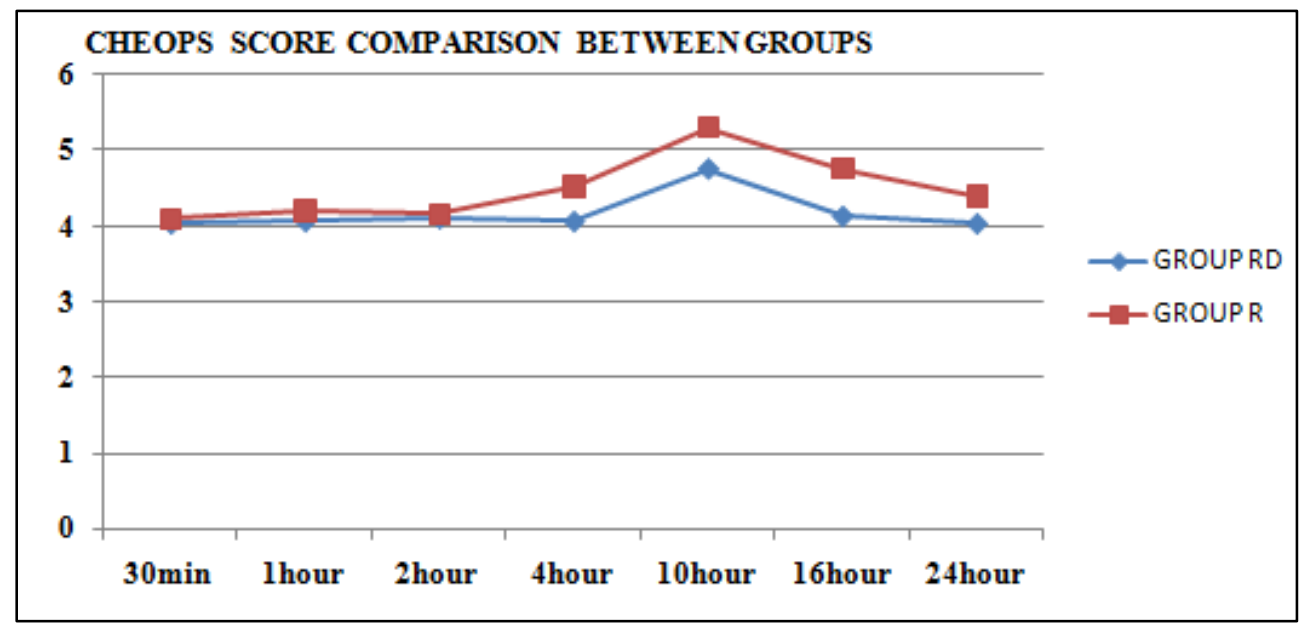

Fig. 4: CHEOPS score comparison between groups

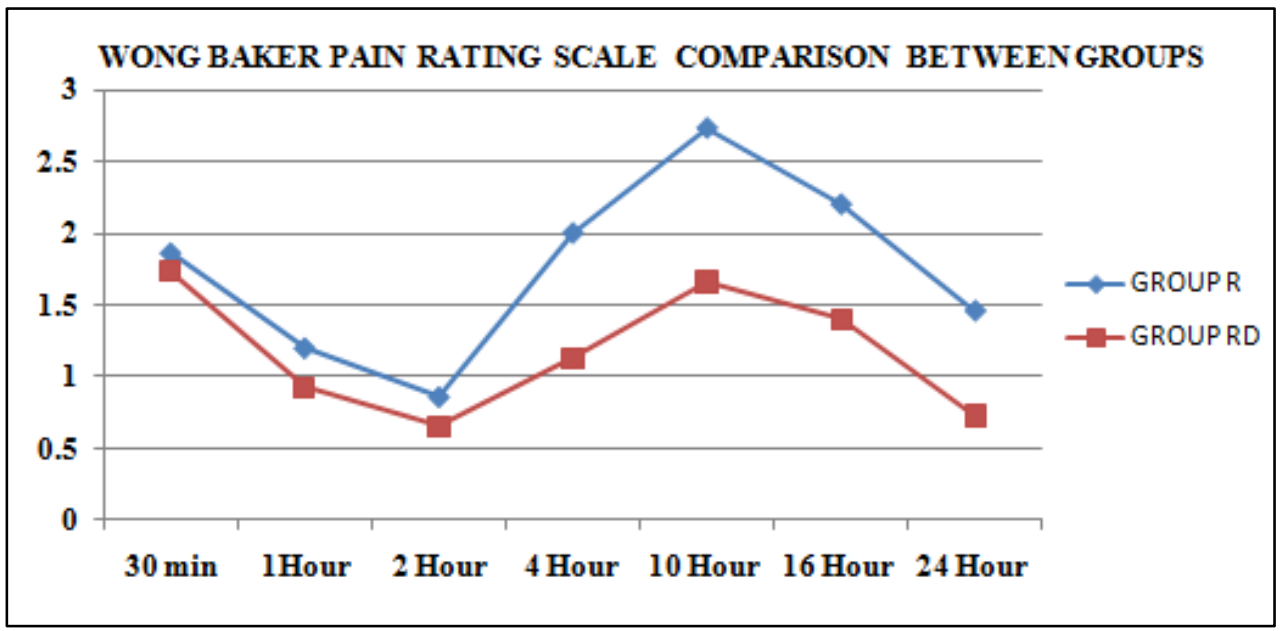

Fig. 5: WBPRS comparison between groups

\section{Discussion}

Tonsillectomy is a short-stay operation performed routinely in many institutions in pediatric age group. It is often associated with intense pain that may not only delay discharge of the patient but also influence his ability to return to normal daily activities. Patients may even be reluctant to eat and drink due to dysphagia. ${ }^{11}$ Throat pain after tonsillectomy is mainly due to irritation of open nerve endings (the glossopharyngeal and vagus nerve) and spasm of the exposed pharyngeal and palatal muscles as a result of mechanical or thermal damage of surrounding tissue. ${ }^{12}$ Peritonsillar infiltration irrespective of the medication used provide superior postoperative analgesia compared to 
placebo infiltration manifested as significantly longer duration of postoperative analgesia, lower postoperative pain scores and less consumption of rescue analgesia with shorter hospital stay. ${ }^{13}$

To allow a smooth recovery and a peaceful return to normal activities, pain relief after tonsillectomy should be effective. Therefore, newer surgical techniques and techniques for analgesia are constantly being updated for better outcome. Among the various surgical techniques, cold dissection is the most widely performed with the advantages of cost-effectiveness and less trauma to surrounding tissues. Most common surgical technique used in our institute is conventional snare technique and for post-operative analgesia gauze piece soaked in lignocaine with adrenaline are packed in peri-tonsillar fossa after tonsillectomy and achievement of haemostasis. There are different other ways of achieving analgesia using local anaesthetics, which include pre-incisional or post-tonsillectomy peritonsillar infiltration. A study compared effect of pre vs. postoperative tonsillar infiltration using local anaesthetics on post tonsillectomy pain conclude that pre or post-operative timing has no clinical significance. ${ }^{14}$

Various local anaesthetic like lignocaine, bupiacaine, ropivacaine has been studied and it was found that ropivacaine is superior to other local anaesthetic agent as it is less lipophilic than bupivacaine and is less likely to penetrate large myelinated motor fibers, resulting in relatively reduced motor blockade thus has a greater degree of motor sensory differentiation which could be useful when motor blockade is undesirable as in peri-tonsillar fossa. ${ }^{13,15,16}$ Motor blockade in peri-tonsillar fossa may result in difficulty in deglutition due to paralysis of pharyngeal muscle. Alpha-2 agonist has peripheral analgesic effect, ${ }^{17}$ and there are several studies which suggest dexmeditomidine, as an adjuvant with local anaesthetic increases efficacy and duration of action of local anaesthetic. ${ }^{9-10}$

While searching through internet and Cochrane data base, no study was done till date which compare ropivacaine with or without dexmeditomidine in post-operative peritonsillar infiltration for post tonsillectomy pain however, a study ${ }^{18}$ compared ropivacaine with or without clonidine in pre-incisional peri-tonsillar infiltration and concluded that pre-incisional injection of ropivacaine with clonidine has better and prolonged analgesic effect and less VAS score compared to ropivacaine and this result is similar to result of our study, however we have done post tonsillectomy infiltration using dexmeditomidine which is more specific and selective alpha 2 agonist with a shorter elimination halflife.

Apart from VAS, objective scales like Children's Hospital of Eastern Ontario Pain Scale (CHEOPS) and Wong baker pain rating score were also used for pain assessment in this study, being more objective considered more reliable. A study uses CHEOPS score for post-operative post tonsillectomy pain assessment in children aged (5-12yr) however they compared peri-tonsillar and intravenous dexmeditomidine in children undergoing tonsillectomy and concluded that CHEOPS score was significantly less in intravenous group $(6.98 \pm 0.86)$ as compared to infiltration group (7.12 \pm 0.81$)$ but Ramsay sedation score was significantly more in intravenous group as compared to peri tonsillar infiltration group. ${ }^{15}$

Another study uses Wong baker pain rating score for pain assessment, however they have compared ropivacaine, bupivacaine and concluded that mean Wong baker pain rating score was less in ropivacaine group $(3.18 \pm 1.50)$ as compare to bupivacaine $(3.82 \pm 1.98){ }^{16}$

As stated earlier there is no similar studies comparing duration of analgesic action of ropivacaine with or without dexmeditomidine in peritonsilar infiltration, but a study ${ }^{13}$ compared ketamine and ropivacaine and concluded that time for first request of analgesia was significantly prolonged in ropivacaine group $(5.52 \pm 2.7 \mathrm{hr})$ as compared to ketamine group (3.83 $\pm 0.16 \mathrm{hr})$ and was comparable to above study. Another study ${ }^{15}$ comparing intravenous and peri-tonsillar infiltration of dexmeditomidine concluded that time for first analgesic requirement was significantly prolonged in intravenous dexmeditomidine group $(9.72 \pm 2.63)$ as compared to peri-tonsillar infiltration group $(8.95 \pm 1.76)$.

In the present study analgesic consumption in 24 hours was significantly lower in group RD group as compared to $\mathrm{R}$ group and results are comparable with a study, ${ }^{18}$ however they had used clonidine as an adjuvant and codeine as rescue analgesia.

Post-operative bleeding was significant low in group RD $(1.13 \pm 0.34)$ as compare to that in group $\mathrm{R}$ it is $(1.36 \pm 0.49)$ ( $\mathrm{P}$ value $<0.05)$. A study which has compare ropivacaine with or without clonidine after pre-incisional peri tonsillarinfiltration concluded that amount of intraoperative blood loss was significantly low in clonidine with ropivacaine group compare to ropivacaine group however this conclusion was for intraoperative blood loss. ${ }^{18}$

Parent's satisfaction score was significantly more in group $\mathrm{RD}(2.80 \pm 0.40)$ compare to that $(1.96 \pm 0.31)$ in group $\mathrm{R}(\mathrm{P}<0.05)$. A study which has compared peri-tonsillar and intravenous dexmeditomidine has concluded that family satisfaction score is significantly higher in peri-tonsillar infiltration group as compare to intravenous group. ${ }^{15}$

We did not found any complication in any case.

The factor that could limit our results is variation in surgeon, being in teaching institute we could not keep single surgeon for all tonsillectomy surgery.

As there were no studies which have compared postoperative peri-tonsillar infiltration of ropivacaine without dexmeditomidine more clinical trials needed for the global acceptance of this study.

\section{Conclusion}

Peritonsillar infiltration using ropivacaine with or without dexmeditomidine is an effective and safe method for post tonsillectomy pain relief, however addition of dexmeditomidine as an adjuvant further increases its efficacy, increases time for first analgesic requirement, decreases total analgesic requirement, decreases pain on deglutition, decreases amount of bleeding and increases parents satisfaction score without added complication. 
So we recommend use of ropivacaine and dexmeditomidine as a postoperative peri-tonsillar infiltration for post tonsillectomy pain relief.

\section{Conflict of Interest: None.}

\section{References}

1. Hydri AS, Nawaid M, Afridi J, Shabbir G: Comparison of local application versus infiltration of Bupivacaine for post Tonsillectomy pain in Adults. Ann Pak Inst Med Sci 2012;8(1):3-5.

2. Nusret İnci, Oguz Basut, Fikret Kasapoglu, Hakan Coşkun.: Management of pain after tonsillectomy. A prospective, randomized clinical study. Kulak Burun Bogaz Ihtis Derg 2009;19(1):1-8

3. Cook SP: Bupivacaine injection to control tonsillectomy pain. Arch Otolaryngol Head Neck Surg 2001;127:1279.

4. Murthy P, Laing MR. Dissection tonsillectomy: pattern of post-operative pain, medication and resumption of normal activity. J Laryngol Otol 1998;112:41-4.

5. Nikandish R, Maghsoodi B, Khademi S, Motazedian S, Kaboodkhani R: Peritonsillar infiltration with bupivacaine and pethidine for relief of post tonsillectomy pain: a randomized double blind study. Anaesth 2008; 63(1):20-5.

6. Hydri AS, Nawaid M, Afridi J, Shabbir G: Comparison of local application versus infiltration of Bupivacaine for post Tonsillectomy pain in Adults. Ann Pak Inst Med Sci 2012;8(1):3-5.

7. Nusret İnci, Oguz Basut, Fikret Kasapoglu, Hakan Coşkun.: Management of pain after tonsillectomy. A prospective, randomized clinical study. Kulak Burun Bogaz Ihtis Derg 2009;19(1):1-8

8. Cook SP: Bupivacaine injection to control tonsillectomy pain. Arch Otolaryngol Head Neck Surg 2001;127:1279.

9. Murthy P, Laing MR. Dissection tonsillectomy: pattern of post-operative pain, medication and resumption of normal activity. J Laryngol Otol 1998;112:41-4.

10. Nikandish R, Maghsoodi B, Khademi S, Motazedian S, Kaboodkhani R: Peritonsillar infiltration with bupivacaine and pethidine for relief of post tonsillectomy pain: a randomized double blind study. Anaesth 2008; 63(1):20-5.

11. Kasapoglu F, Kaya FN, Tuzemen G, Ozmen OA, Kaya A, Onart S: Comparison of peritonsillar levobupivacaine and bupivacaine infiltration for post-tonsillectomy pain relief in children: placebo-controlled clinical study. Int $J$ Pediatr Otorhinolaryngol 2011;75(3):322-6.

12. Khademi Saeed, Ghaffarpasand Fariborz, Heiran Hamid Reza, Yavari Mohammad Javad, Motazedian Siavash, Dehghankhalili, Maryam: Intravenous and peritonsillar infiltration of ketamine for postoperative pain after adenotonsillectomy: a randomized placebo-controlled clinical trial. Med Princ Pract 2011;20(5):433-7.

13. Ertap Akoglu, B. Cagla Ozbakıs Akkurt, Kerem Inanoglu, Semsettin Okuyucu, Safak Daglı: Ropivacaine compared to bupivacaine for post-tonsillectomy pain relief in children: A randomized controlled study. Int J Pediatr Otorhinolaryngol 2006;70:1169-73.

14. Fritsch G, Danninger T, Allerberger K. Dexmedetomidine added to ropivacaine extends the duration of interscalene brachial plexus blocks for elective shoulder surgery when compared with ropivacaine alone: a single-center, prospective, triple-blind, randomized controlled trial. Reg Anaesth Pain Med 2014;39:37-47.

15. Marhofer D, Kettner SC, Marhofer P, Pils S, Weber M, Zeitlinger M: Dexmedetomidine as an adjuvant to ropivacaine prolongs peripheral nerve block: a volunteer study. $\mathrm{Br} J$ Anaesth 2013;110:438-42.
16. Ayman H. Salah Eldin: Role of Platelet-Rich Plasma to Decrease Post Tonsillectomy Pain and Bleeding. Med J Cairo Univ 2011;79(2):175-8.

17. Freeman SB, Markwell JK: Sucralfate in alleviating post tonsillectomy pain. Laryngoscope 1992;102:1242-6.

18. Manal S. Farmawy, Manal M. Rashad: Preemptive analgesia by peritonsillar ketamine versus ropivacaine for posttonsillectomy pain in children: Egypt J Anaesth 2014;30:1-5.

19. Molliex S. Haond P. Baylot D. Prades J. M. Navez M. Elkhoury Z. Auboyer C: Effect of pre- vs postoperative tonsillar infiltration with local anaesthetics on postoperative pain after tonsillectomy. Acta Anaesthesiol Scand 1996;40(10):1210-5.

20. Hala S. Abdel-ghaffar, Alaa Kamel Abdel-Haleem: Efficacy and safety of intraoperative dexmedetomidine in pediatric post tonsillectomy pain: Peritonsillar Versus intravenous administration: Egypt J Anaesth 2011;27:219-25.

21. Goutham M K, Ravishankara S, Sudhir M Naik, Sathya P, Mohan Appaji, Shankarnarayan Bhat: Comparison of local infiltration of ropivacaine, bupivacaine, topical application of sucralfate in the tonsillar fossa on post-tonsillectomy pain: Otolaryngol Online J 2014;4(4).

22. Al-Metwalli RR, Mowafi HA, Ismail SA, Siddiqui AK, AlGhamdi AM, Shafi MA: Effect of intra-articular dexmedetomidine on postoperative analgesia after arthroscopicknee surgery. Br J Anaesth 2008;101(3):395-9.

23. Carla giannoni, F. Kayser Enneking, Timothy Morey, Ropiacaine with or without clonidine improves pediatric tonsillectomy pain. Arch Otolaryngol Head Neck Surg $2001 ; 127$.

How to cite this article: Singh R, Trivedi LH, Parmar RM. Comparison of the efficacy of ropivacaine and ropivacaine with dexmeditomidine in post tonsilectomy pain relief after peritonsillar infiltration- A prospective randomized double blind study. Indian J Clin Anaesth 2019;6(2):263-9. 